\title{
Biofilm formation of Clostridium difficile and susceptibility to Manuka Honey
}

\author{
Eric N Hammond ${ }^{1 *}$, Eric S Donkor ${ }^{2}$ and Charles A Brown ${ }^{3}$
}

\begin{abstract}
Background: Biofilm bacteria are relatively more resistant to antibiotics. The escalating trend of antibiotic resistance higlights the need for evaluating alternative potential therapeutic agents with antibacterial properties. The use of honey for treating microbial infections dates back to ancient times, though antimicrobial properties of Manuka honey was discovered recently. The aim of this study was to demonstrate biofilm formation of specific Clostridium difficile strains and evaluate susceptibility of the biofilm to Manuka honey.

Methods: Three C. difficile strains were used in the study including the ATCC 9689 strain, a ribotype 027 strain and a ribotype 106 strain. Each test strain was grown in sterile microtitre plates and incubated at $37^{\circ} \mathrm{C}$ for 24 and 48 hours in an anaerobic cabinet to allow formation of adherent growth (biofilm) on the walls of the wells. The effect of Manuka honey on the biofilms formed was investigated at varying concentrations of $1-50 \%(\mathrm{~W} / \mathrm{V})$ of Manuka honey.

Results: The three $C$. difficile strains tested formed biofilms after 24 hours with the ribotype 027 strain producing the most extensive growth. There was no significant difference $(p>0.05)$ found between the amount of biofilms formed after 24 and 48 hours of incubation for each of the three $C$. difficile strains. A dose-response relationship between concentration of Manuka honey and biofilm formation was observed for all the test strains, and the optimum Manuka honey activity occurred at $40-50 \%(\mathrm{v} / \mathrm{v})$.
\end{abstract}

Conclusion: Manuka honey has antibacterial properties capable of inhibiting in vitro biofilm formed by C. difficile.

Keywords: Clostridium difficile, Biofilm, Manuka honey, Antibacterial, Susceptibility

\section{Background}

Biofilms are complex structures of polysaccharide matrix excreted by bacteria in a form of slimy, glue-like substance that adhere to material surfaces especially, when exposed to some amount of water [1]. Within the last decade, many studies have been done on biofilms which have established their association with infections and contaminations [1]. The conventional methods of killing bacteria by using antibiotics and disinfection are often unsuccessful with biofilm forming bacteria [1]. Thus biofilm forming bacteria may pose a relatively greater threat to public health. For instance, it is reported that patients suffering from biofilm associated infections tend to stay longer in hospital than expected [2,3]. Worldwide, it is estimated that biofilms are associated with 65 percent of

\footnotetext{
* Correspondence: hammondes@yahoo.com

'Department of Microbiology, University of Wales Institute Cardiff, Cardiff CF1 3TL, UK

Full list of author information is available at the end of the article
}

nosocomial infections and contribute to high death rate and $2-14 \%$ of all surgical wounds complications [2]. Biofilm formation by bacteria also has serious economic implications. It is reported that a microorganism associated with biofilm formation is reported to cost some nations billions of dollars yearly in medical infections, equipment damage and product contamination [4].

Some bacterial organisms known to form biofilms include Pseudomonas aeruginosa, Staphylococcus aureus, Listeria monocytogenes and Clostridium difficile [5,6]. Biofilm formation by $C$. difficile was first reported in 2012 and has since then been demonstrated with a few strains of the organism [7-10]. Evidence from some studies indicate that amount of biofilm formed by $C$. difficile varies from strain to strain [4,5]. Mutagenesis studies have identified several surface proteins such as SlecC, Cwp84 and LuxS that are required for biofilm formation of $C$. difficile $[8,10]$. There is also evidence that some level of sporulation occurs in C. difficile biofilm [11,12]. 
The use of honey for treating microbial infections dates back to ancient times, though antimicrobial properties of Manuka honey was discovered recently. The antibacterial effect of Manuka honey against bacterial biofilms has been demonstrated for several organisms such as Streptococcus pyogenes [13], Pseudomonas aeruginosa [14], Enterococcus faecalis [15] and Streptococcus mutans [16]. Bactericidal effects have been found in both planktonic cultures and biofilm, although higher concentrations were required to inhibit biofilms [17]. In a biofilm study, Maddocks et al. [17] reported that sublethal concentrations of Manuka honey disrupted the binding of $S$. pyogenes to the human fibronectin but did not prevent binding to fibrinogen. Manuka honey thus appears to be a promising antibacterial agent in this era of diminishing antimicrobial agents. However, further studies on its antibacterial properties are required especially, with highly resistant pathogens such as $C$. difficile.

C. difficile, the causative agent of severe inflammation of the bowel (pseudomembranous colitis), has become the most significant nosocomial antibiotic-associated diarrhoea reported worldwide [18,19]. The Centers for Disease Control and Prevention (CDC) estimate that nearly 250,000 serious C. difficile infections (CDI) occur in the US annually, at a cost of at least one billion dollars, resulting in 14,000 deaths (CDC, 2013) [20]. This high public health burden associated with $C$. difficile is partly due to the trend of increasing resistance of the organism to several essential antibiotics, a problem which highlights the need for alternative treatment methods of C. difficile infections. In a previous study, we demonstrated the susceptibility of $C$. difficile to Manuka honey (Leptospermum scoparium) [21]. The findings of the study showed that Manuka honey exhibits a bactericidal activity against $C$. difficile with minimum inhibitory and bactericidal concentrations of $6.25 \%$ (v/v) [21]. However, it is unknown if biofilm formed by $C$. difficle is also susceptible to Manuka honey. Biofilm formation by $C$. difficile in itself has been recently reported, and it is important to confirm this with various $C$. difficile strains. The aim of this study was to demonstrate biofilm formation of specific strains of $C$. difficile and the antibacterial effect of Manuka honey on the $C$. difficile biofilm.

\section{Methods}

\section{Clostridium difficile strains}

Three $C$. difficile strains were used for the experiments in this study, and they included the ATCC 9689 strain, a ribotype 027 strain and a ribotype 106 strain. These strains were selected for the study due to their epidemiological or clinical significance. The $C$. difficile strains were obtained from University of Wales Hospital and were maintained in Robertson's Cook meat medium (Oxoid, Cambridge, UK) at the Department of Microbiology,
University of Wales Institute Cardiff where the study was carried out. Prior to using the C. difficile strains in the experimental work, they were purified on blood agar plates.

\section{Manuka honey}

Woundcare $^{\mathrm{TM}}$ 18+ Active Manuka honey (potency equivalent of greater than $18 \%(\mathrm{w} / \mathrm{v})$ phenol) with non-peroxide antibacterial activity from Comvita UK was used in this study.

\section{Microtitre plate assay for the assessment of biofilm formation in $\mathrm{C}$. difficile strains}

The experiments performed to determine the capability of the $C$. difficile strains to form biofilms were based on the previously described methods [4]. The three C. difficile test strains were cultured overnight in Reinforced Clostridial Medium (RCM) broth at $37^{\circ} \mathrm{C}$ for 24 hours. For each strain, a dilution of 1:100 inoculum was made in a sterile broth bottle by pipetting $1 \mathrm{ml}$ of each strain into $99 \mathrm{ml}$ of RCM broth and vortexing to achieve a good mixture. An aliquot of $200 \mu \mathrm{l}$ of each diluted inoculum was dispensed into a 96-well Nunc flat bottom microtitre plate. The plates and contents were incubated at $37^{\circ} \mathrm{C}$ for 24 and 48 hours in an anaerobic cabinet to allow for formation of biofilms on the walls of the wells. For each experiment, wells of RCM broth without $C$. difficile strains were used as negative control. At the end of the 24 and 48 hours of incubation, the plates were removed from the anaerobic cabinet and the cultures were carefully removed by using a Pasteur pipette. Subsequently, $200 \mu \mathrm{l}$ of $2.5 \%$ glutaraldehyde solution was pipetted into each of the drained wells, and allowed to stand for 5 minutes to allow fixation. The glutaraldehyde solution was then removed and the empty wells were washed by dispensing $200 \mu \mathrm{l}$ of phosphate buffered saline (PBS) (Oxoid, Cambridge, UK) in them. The PBS was discarded and the wells were stained with $200 \mu \mathrm{l}$ of $0.25 \%$ (w/v) aqueous crystal violet for 5 minutes. After this time, the wells were washed with PBS eight times and allowed to air dry. The quantity of biofilm formed was analyzed by adding $200 \mu$ l solvent (1:1 ethanol and acetone solution) to each well to dissolve dye from adherent cells (biofilm). Absorbance was measured within 5 minutes of adding the solvent at $570 \mathrm{~nm}$ using a Dynex plate reader. The microtitre plate biofilm assay was performed three times on separate occasions for all test $C$. difficile strains.

\section{Determination of the effect of various honey concentrations on $\mathrm{C}$. difficile biofilms}

The three $C$. difficile test strains were cultured overnight in an RCM broth at $37^{\circ} \mathrm{C}$ for 24 hours. For each strain, an aliquot of $200 \mu \mathrm{l}$ of each diluted inoculum (as described in Section 3.3) was dispensed into each well of a 96-microtitre plate, starting from the first column (Column 
1) which contained inoculum but no Manuka honey (positive control). The last column (Column 12) contained RCM only (no inoculum) and was used as a negative control. Outer rows and columns were unused, except for column 12 to avoid edge effects. The plates were incubated at $37^{\circ} \mathrm{C}$ for 24 hours in an anaerobic cabinet to allow for the formation of biofilms on the walls of the wells. After incubation, a sterile Pasteur pipette was used to carefully remove the liquid phase containing any planktonic growth from each well into a discard jar, leaving adherent biofilm attached to the well walls. However the positive control was re-filled with $200 \mu \mathrm{l}$ RCM to keep the biofilm alive. With the exception the negative control wells, each well was re-filled with $200 \mu \mathrm{l}$ of Manuka honey solutions and incubated at $37^{\circ} \mathrm{C}$ for 24 hours in an anaerobic cabinet. Different concentrations of Manuka honey $(0,1,2,4,8$, $10,20,30,40,50 \%(\mathrm{w} / \mathrm{v}))$ were included in the experimental setup and were prepared by dilutions with RCM.

After incubation, the liquid phase in each well (containing any overnight planktonic growth together with the honey solutions) was discarded into the discard jar using a sterile Pasteur pipette. The adherent growth was fixed with $200 \mu \mathrm{l}$ of $2.5 \%$ glutaraldehyde for 5 minutes. The fixative was removed into a toxic waste bottle and the wells washed twice with PBS. All the wells were stained with $200 \mu \mathrm{l}$ of $0.25 \%$ crystal violet for 5 minutes. The stain was then removed and the wells washed 8 times with PBS. It was ensured that any remaining liquid was drained from the plates by inverting them vigorously onto paper hand towels. At this point, biofilms were visible as purple rings formed on the side of each well. The quantity of biofilms formed were analysed by adding $200 \mu \mathrm{l}$ solvent (1:1 ethanol and acetone solution) to each well to dissolve dye associated cells. The reading was taken (within 5 minutes of adding the solvent) at $570 \mathrm{~nm}$ in a Dynex plate reader. The microtitre plate biofilm assay was performed three times on separate occasions for all $C$. difficile test strains.

\section{Statistical analysis}

The experimental data was entered into Microsoft Excel ${ }^{\odot}$ 2010 and analyzed. Mean biofilm biomass was calculated for each $C$. difficile strain at 24 and 48 hours. The Student's $t$-test was used to test for any significant difference between biofilms formation as function of the hours for the different strains. A $p$-value less than or equal to 0.05 was considered significant.

\section{Results and discussion}

In this study we investigated biofilm formation of $C$. difficile and the susceptibility to Manuka honey. Figure 1 shows that all the three $C$. difficile strains formed biofilms and there was no significant difference $(p=0.3901)$ between biofilm formation in 24 hours and biofilm formation in 48 hours.

Bacterial biofilm formation occurs through an interesting mechanism which first involves bacterial attachment to a material surface. This initial attachment of the bacterial organism is influenced mainly by combination of environmental factors (such as nutrient levels, temperature, $\mathrm{pH}$ and duration of attachment) and genetic factors [1]. Immediately the cells are attached to suitable surfaces, they begin to multiply and grow to form a thin layer (monolayer) towards where conditions are favourable on material surfaces. At this stage, the cells undergo a developmental change which lead to the production of a complex structure referred to as exopolysaccharide glycocalyx polymers matrix and is one of the hallmarks of a matured biofilm [22-24].

The ability of $C$. difficile to form biofilms as observed in this study concurs with studies carried out by several other investigators [7-10]. As shown in Figure 1, among

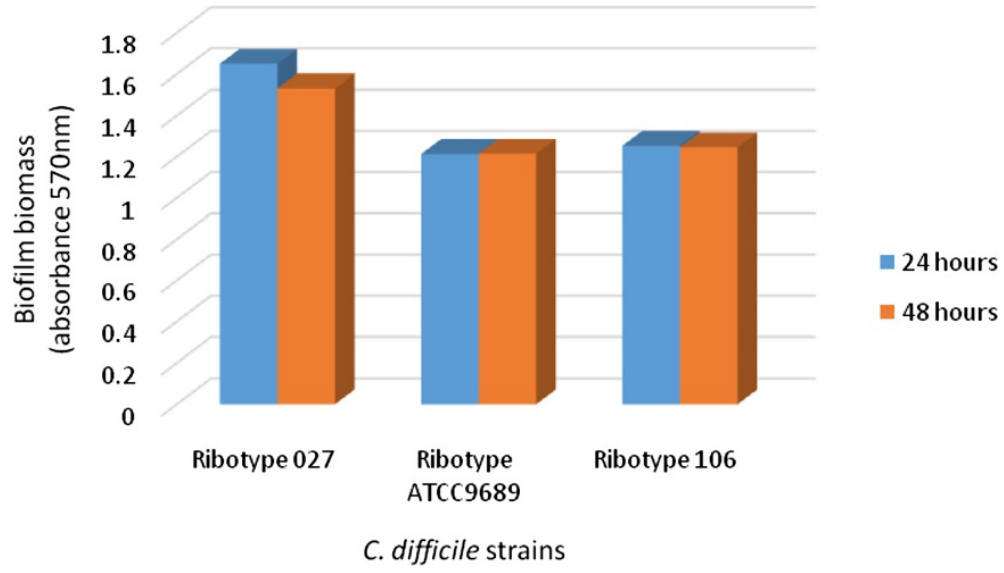

Figure 1 Formation of adherent growth (biofilm) by C. difficile strains after 24 and 48 hours incubation. 
the three $C$. difficile strains, the ribotype 027 strain showed the highest potential for biofilm formation. Biofilm formation has been linked with virulence of several bacterial pathogens including $C$. difficile $[8,13]$. C. difficile of ribotype 027 is known to be a hypervirulent strain and the commonest cause of $C$. difficile associated outbreaks [25]. Data from our study appear to indicate that the high virulence and epidemiological significance of $C$. difficile ribotype 027 strains may be related to its relatively greater ability to form biofilms compared to other $C$. difficile strains such as ribotype 106 strains. In their study of $C$. difficile biofilm, Dapa et al. [8] also observed that the hypervirulent strain (ribotype 027) produced more biofilm than a less virulent $C$. difficile strain. Currently, very little is known about the actual role of biofilm in the pathogenicity and pathogenesis of $C$. difficile, and further studies are required to elucidate this.

The extent of Manuka honey inhibiting the established biofilm was determined by comparing the amount of biofilm formed in the wells with and without Manuka honey. This experiment showed that generally, there was a dose-response relationship between the amount of biofilm depleted and concentration of Manuka honey (Figure 2). Concentrations of Manuka honey below 20\% $(\mathrm{w} / \mathrm{v})$ appeared to have no or little effect on the established biofilm for each of the three $C$. difficle strains. However, concentrations between 20 and $50 \%$ (w/v) Manuka honey resulted in decreasing amount of biofilm formed by all test strains after 24 hours. Although MIC and MBC of Manuka honey against suspensions of the C. difficile strains used in this study were $6.25 \%(\mathrm{v} / \mathrm{v})$ [21], much higher concentrations of $30-50 \%(\mathrm{w} / \mathrm{v})$ of Manuka honey were required to deplete biofilms formed by the $C$. difficile strains.

This may be due to the ability of the sessile bacteria (biofilm formed by $C$. difficile) to secrete proteins and polymeric sugars which serve as a protection to enhance quorum development for survival [1]. Similar results were reported by Okhiria et al. [26]. Fux et al. [27] showed that biofilms are strongly resistant to biocides, drying and most environmental stresses. Ashby et al. [28] and Costerton et al. [29] reported that the ability of biofilm to resist antibiotic effect could be due to the slow growth rate of biofilm, since the effect of bactericides on biofilm usually declines with lower growth rate.

From this study, it may be inferred that the most suitable Manuka honey concentrations to inhibit C. difficile biofilm significantly were 40 and $50 \%(w / v)$. Similarly, Okhiria et al. [26] reported that Pseudomonas biofilm exposed to $40 \%(\mathrm{w} / \mathrm{v})$ Manuka honey concentration showed a significant inhibition, but 20\% (w/v) Manuka honey did not show any significant inhibition. From Figure 2, it can be observed that Manuka honey could not exhibit $100 \%$ depletion of biofilm formed by the $C$. difficile strains. Studies by Alandejani et al. [30] also reported that the effectiveness of Manuka honey against biofilms formed by $S$. aureus and $P$. aeruginosa were less than $100 \%$. Nevertheless, based on this study and others, it is important to note that Manuka honey has an appreciable antibacterial activity against biofilm formed by bacterial organisms [31]. While in this study we demonstrated the ability of Manuka honey to inhibit biofilm formation of $C$. difficile, Maddock et al. [17] demonstrated the ability of Manuka honey to disrupt preformed biofilms of Streptococcus pyogenes. Recently, Ansari et al. [31] also reported that Jujube honey can disrupt pre-formed biofilms of Candida albicans. Antimicrobial effect of Manuka honey is due to a property referred to as Unique Manuka Factor that is absent in other types of honey [32]. Various studies have revealed that the active ingredient in Manuka honey is Methylglyoxal [33,34], and this compound is known to have

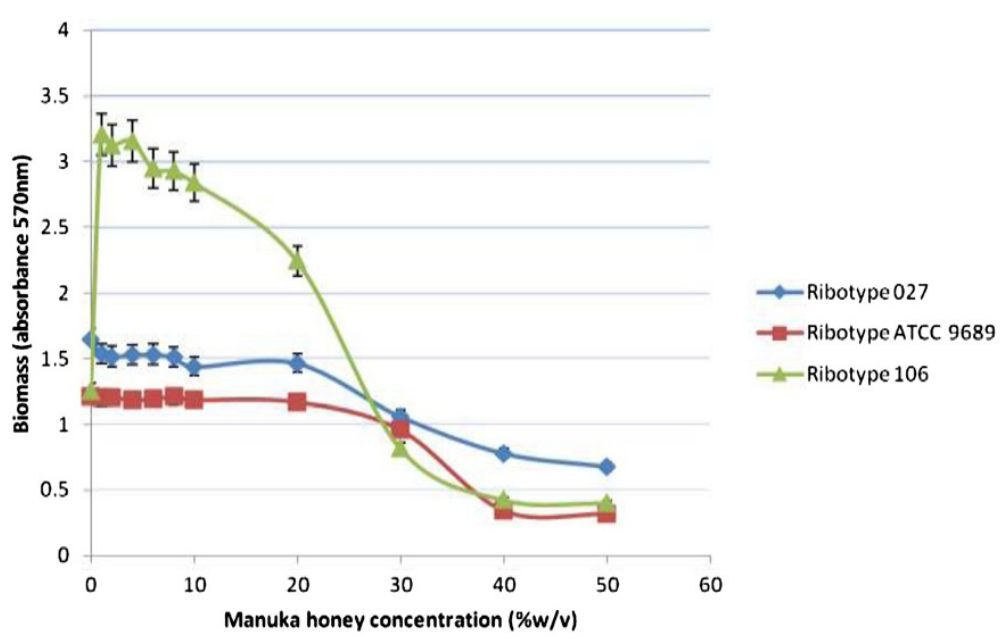

Figure 2 The effect of varying concentrations of Manuka honey on biofilm of $C$. difficile strains. 
synergistic effect with some antibiotics such as piperacillin [35].

We previously demonstrated susceptibility of $C$. difficile to Manuka honey, and in this study, have also shown that biofilm formed of the organism is similarly susceptible to Manuka honey. Overall these findings have important applications in the treatment of $C$. difficile infections given the escalating trend of the organism to several essential antibiotics. In the light of the findings of the current study, it is also important for further studies to determine the rate and concentrations at which Manuka honey inhibits biofilms of $C$. difficile in vivo. Additionally, it would useful to investigate the effect of Manuka honey on spores of $C$. difficile.

\section{Conclusions}

In this study, we have demonstrated biofilm formation of specific C. difficile strains including ATCC 9689, ribotype 027 and ribotype 106 . We have also shown that Manuka honey exhibits antibacterial activity against $C$. difficile biofilm with the optimum activity occurring at $40-50 \%(\mathrm{w} / \mathrm{v})$. The bactericidal action of Manuka honey may be exploited practically by incorporating a solution of $40-50 \%(\mathrm{w} / \mathrm{v})$ Manuka honey in topical and handwashing formulations in care homes and hospitals or places where $C$. difficile populations are likely to be high.

\section{Competing interests}

The authors declare that they have no competing interests.

\section{Authors' contributions}

Laboratory experiments were carried out by ENH. Interpretation of the data was done by ENH, ESD and CAB. The manuscript was written by ESD, ENH and $C A B$. All authors read and approved the manuscript.

\section{Acknowledgement}

The authors thank staff of Department of Microbiology, University of Wales Institute Cardiff, UK for the advice and technical assistance they provided during the study. The authors also thank Mrs Evelyn A.S Hammond of Central University College (Dept. of Environment and Development Studies) in Ghana for the suggestions she provided to improve the manuscript.

\section{Author details}

${ }^{1}$ Department of Microbiology, University of Wales Institute Cardiff, Cardiff CF1 3TL, UK. ²Department of Microbiology, University of Ghana Medical School, Accra, Ghana. ${ }^{3}$ Department of Medical Laboratory Sciences, School of Allied Health Sciences, University of Ghana, Accra, Ghana.

Received: 23 May 2014 Accepted: 27 August 2014

Published: 3 September 2014

\section{References}

1. Wolcott R, Cutting KF, Dowd SE: Surgical site infections: biofilms, dehiscence and delayed healing. Wound UK 2008, 4(4):110-112.

2. Donlan RM: Biofilms and device-associated Infections. Emerg Infect Dis 2001, 7(2):277-281

3. Rosenthal VD: Device-associated nosocomial infections in limitedresources countries: Findings of the International Nosocomial Infection Control Consortium (INICC). Am J Infect Control 2008, 36(10):171.e7-12.

4. Denkhaus E, Meisen S, Telgheder U, Wingender J: Chemical and physical methods for characterisation of biofilms. Microchimica Acta 2007, 158(1-2):1-27
5. Cooper RA, Jenkins L: The inhibition of biofilms of Pseudomonas aeruginosa with Manuka honey. Ostomy Wound Manage 2008, 54(4):70.

6. Oliveria M, Numes SF, Carneiro C, Bexiga R, Bernardo F, Vilela CL: Time course of biofilm formation by Staphylococcus aureus and Staphylococcus epididermidis mastitis isolates. Vet Microbiol 2007, 124(1-2):187-191.

7. Dawson LF, Valiente E, Faulds-Pain A, Donahue EH, Wren BW: Characterisation of Clostridium difficile Biofilm Formation, a Role for Spo0A. PLoS One 2012, 7(12):e50527.

8. Dapa T, Leuzzi R, Ng YK, Baban ST, Adamo R, Kuehne SA, Scarselli M, Minton NP, Serruto D, Unnikrishnan M: Multiple factors modulate biofilm formation by the anaerobic pathogen Clostridium difficile. J Bacterio/ 2013, 195(3):545-555.

9. Donelli G, Vuotto C, Cardines R, Mastrantonio P: Biofilm-growing intestinal anaerobic bacteria. FEMS Immunol Med Microbiol 2012, 65(2):318-325.

10. Dapa T, Unnikrishnan M: Biofilm formation by Clostridium difficile. Gut Microbes 2013, 4(5):397-402.

11. Semenyuk EG, Laning ML, Foley J, Johnston PF, Knight KL, Gerding DN, Driks A: Spore formation and toxin production in Clostridium difficile biofilms. PLoS One 2014, 9(1):e87757.

12. Crowther GS, Chilton CH, Todhunter SL, Nicholson S, Freeman J, Baines SD, Wilcox $\mathrm{MH}$ : Development and validation of a chemostat gut model to study both planktonic and biofilm modes of growth of clostridium difficile and human microbiota. PLoS One 2014, 9(2):e88396.

13. Lembke C, Podbielsk A, Hidalgo-Grass C, Jona L, Hanski E, Kreikemeyer B: Characterization of biofilm formation by clinically relevant serotypes of group A streptococci. Appl Environ Microbiol 2006, 72:2864-2875.

14. Klausen M, Heydorn A, Ragas P, Lambertsen L, Aaes-Jorgensen A, Molin S, Tolker-Nielsen T: Biofilm formation by Pseudomonas aeruginosa wild type, flagella and type IV pili mutants. Mol Microbiol 2003, 48:1511-1524.

15. Hancock LE, Perego M: The Enterococcus faecalis fsr two-component system controls biofilm development through production of gelatinase. J Bacteriol 2004, 186:5629-5639.

16. Cvitkovitch DG, Li YH, Ellen RP: Quorum sensing and biofilm formation in streptococcal infections. J Clin Investig 2003, 112:1626-1632.

17. Maddocks SE, Lopez MS, Rowlands RS, Cooper RA: Manuka honey inhibits the development of Streptococcus pyogenes biofilms and causes reduced expression of two fibronectin binding proteins. Microbiology 2012, 158:781-790.

18. Rodica G, Bruno H, Elise F, Colette G, Marc D: Epidemiology patterns and hospital characteristics associated with increased incident of Clostridium difficile infection in Qubec, Canada, 1998-2006. Infect Control Hosp Epidemiol 2010, 31(9):939-947.

19. Barbut F, Jones G, Eckert C: Epidemiology and control of Clostridium difficile infections in healthcare settings: an update. Curr Opin Infect Dis 2011, 24(4):370-376.

20. The Centers for Disease Control and Prevention (CDC): Antibiotic resistance threats in the United States, 2013. [www.cdc.gov/drugresistance/threatreport-2013/] [Accessed on 16.09.2010].

21. Hammond E, Donkor ES: Antibacterial effect of Manuka honey on Clostridium difficile. BMC Res Notes 2013, 6:188

22. Answar $\mathrm{H}$, Dasgupta MK, Costerton JW: Testing the susceptibility of bacteria in biofilms to antibacterial agents. Antimicrob Agents Chemother 1990, 34(11):2043-2046.

23. Consterton JW: Overview of microbial biofilms. J Indus Microbial 1995, 15:137-140

24. Danese PN, Pratt LA, Kolter R: Exopolysaccharide production is required for development of Escherichia coli K-12 biofilm architecture. J Bacteriol 2000, 182(12):3593-3596.

25. Freeman J, Bauer MP, Baines SD, J. Corver J, Fawley WN, Goorhuis B, Kuijper EJ, Wilcox MH: The Changing Epidemiology of Clostridium difficile Infections. Clin. Microbiol. Rev. 2010, 23(3):529-549.

26. Okhiria OA, Henriques AFM, Burton NF: Honey modulates biofilms of Pseudomonas aeruginosa in a time and dose dependent manner. J ApiProd ApiMed Sci 2009, 1:6-10.

27. Fux CA, Consterton JW, Stewart PS, Stoodley P: Survival strategies of infectious biofilms. Trends Microbiol 2005, 13(1):34-40.

28. Ashby MJ, Neale JE, Knott SJ, Critchley IA: Effect of antibiotics on nongrowing planktonic cells and biofilms of Escherichia coli. J Antimicrob Chemother 1994, 33:443-452.

29. Consterton JW, Stewart PS, Greenberg EP: Bacterial biofilms: a common cause of persistent infection. Science 1999, 284:1318-1322. 
30. Alandejani T, Marsan JG, Ferris W, Slinger R, Chan F: Effectiveness of honey on S. aureus and P. aeruginosa biofilms. Otolaryngol Head Neck Surg 2008, 14(1):114-118.

31. Ansari MJ, Al-Ghamdi A, Usmani S, Al-Waili NS, Sharma D, Nuru A, Al-Attal Y: Effect of jujube honey on Candida albicans growth and biofilm formation. Arch Med Res 2013, 44(5):352-360.

32. Molan PC, Russell KM: Non-peroxide antibacterial activity in some New Zealand honeys. J Apic Res 1988, 27(1):62-67.

33. Atrott J, Haberlau S, Henle T: Studies on the formation of methylglyoxal from dihydroxyacetone in Manuka (Leptospermum scoparium) honey. Carbohydr Res 2012, 361:7-11.

34. Mavric E, Wittmann $S$, Barth G, Henle T: Identification and quantification of methylglyoxal as the dominant antibacterial constituent of Manuka (Leptospermum scoparium) honeys from New Zealand. Mol Nutr Food Res 2008, 52(4):483-489.

35. Mukherjee S, Chaki S, Das S, Sen S, Dutta SK, Dastidar SG: Distinct synergistic action of piperacillin and methylglyoxal against Pseudomonas aeruginosa. Indian J Exp Biol 2011, 49:547-551.

doi:10.1186/1472-6882-14-329

Cite this article as: Hammond et al:: Biofilm formation of Clostridium difficile and susceptibility to Manuka Honey. BMC Complementary and Alternative Medicine 2014 14:329.

\section{Submit your next manuscript to BioMed Central and take full advantage of:}

- Convenient online submission

- Thorough peer review

- No space constraints or color figure charges

- Immediate publication on acceptance

- Inclusion in PubMed, CAS, Scopus and Google Scholar

- Research which is freely available for redistribution 